\title{
Multivariate analysis as a tool for measuring the stability of morphometric traits in Lycopersicon plants from in vitro culture
}

\author{
Guillermo Pratta, Roxana Zorzoli and Liliana Amelia Picardi
}

\begin{abstract}
The phenotypic stability of morphometric traits in Lycopersicon spp. (stem perimeter at the base, middle and top, and number of flowers per cluster) was measured by multivariate analysis through a progeny test in order to estimate the genetic stability of these traits. Principal components were calculated for two groups of Lycopersicon spp., non-regenerated plants and the progeny of regenerated plants. Analysis of variance was performed to support principal component analysis. Both groups presented similar eigenvalues and eigenvectors, while no significant differences were found between any of the traits studied. These results indicated that the phenotypic structure was the same among the progeny of regenerated and non-regenerated plants, so that no variation would occur in in vitro culture. Multivariate analysis proved to be an appropriate methodology for the measurement of the stability of morphometric traits after one regeneration cycle.
\end{abstract}

\section{INTRODUCTION}

One of the aims of plant regeneration by tissue culture is to produce individuals genetically identical to the explant's donors and to themselves (i.e., a clone). The efficiency of this biotechnological process depends not only on the number of plants obtained in vitro but also on the genetic stability after the regeneration cycles. Somaclonal variants may be produced by in vitro culture (Evans and Sharp, 1983; D’Amato, 1985; Lee and Phillips, 1988), and these heritable changes might produce an increase in genetic variability available for breeding programs, but if cloning genotypes was desired this variation should be minimized (Skirvin et al., 1994). Phenotypic markers showing a known inheritance pattern may be considered to evaluate the genetic stability of the regenerated plants (Gavazzi et al., 1987), and De Klerk (1990) emphasized the importance of the use of metric traits as phenotypic markers to evaluate genetic stability.

Multivariate analysis gives a measure of the total variation in different samples of individuals (Chatfield and Collins, 1986), and it is possible to apply this methodology to the evaluation of modifications of regenerated plants in respect to the explant's donors.

The goal of this experiment was to use principal component analysis to measure the stability of metric traits in tomato (Lycopersicon spp.) plants obtained from in vitro culture after one regeneration cycle with the aim of developing a new approach for detecting the effects of in vitro culture on these traits.

\section{MATERIAL AND METHODS}

Regenerated plants of different genotypes of $L$. esculentum, L. esculentum var. cerasiforme, L. pimpinellifolium, L. peruvianum and L. hirsutum (Pratta et al., 1997) were used (Table I), the in vivo adaptation of the regenerated plants being accomplished according to the protocol described in Pratta et al. (1995). Acclimatized plants were kept in a greenhouse for flowering and fructification.

The stability of metric traits in the in vitro regenerated plants was assessed through a progeny test, for which two groups of plants were assayed: group 1, the experimental group, was non-regenerated plants (NP) consisting of the explant's donor plants $\left(\mathrm{NP}_{1}\right)$ and their progeny $\left(\mathrm{NP}_{2}\right)$ (L. esculentum $(\mathrm{N}=24)$, L. esculentum var. cerasiforme $(\mathrm{N}=19)$, L. pimpinellifolium $(\mathrm{N}=13), L$. peruvianum $(\mathrm{N}=9)$ and L. hirsutum $(\mathrm{N}=7)(\mathrm{N}=72)$ ). Group 2 consisted of the progeny of the regenerated plants (PRP) (L. esculentum ( $\mathrm{N}=12)$, L. esculentum var. cerasiforme $(\mathrm{N}=43)$, L. pimpinellifolium $(\mathrm{N}=14), L$. peruvianum $(\mathrm{N}=1)$ and L. hirsutum $(\mathrm{N}=9)(\mathrm{N}=79))$.

The metric traits evaluated in both groups were stem perimeter (in $\mathrm{cm}$ ) at the base (PB), the middle (PM) and the top (PA) of the plant and the number of flowers per cluster (FC). Seeds of $\mathrm{NP}_{1}$ were sown in the first crop cycle, while seeds of $\mathrm{NP}_{2}$ and PRP were sown in the next cycle. Annual effect was assessed by comparing the mean values for each variable in $\mathrm{NP}_{1}$ plants and $\mathrm{NP}_{2}$ plants with the Student $t$-test (Snedecor, 1964). Analysis of the effect of in vitro culture on plant stability was accomplished by princi- 
pal components (PC) analysis (Chatfield and Collins, 1986), which was applied firstly to the groups to compare respective $\mathrm{PC}$ values, then to the total data in order to test if any modification was produced in the values and lastly to the genotypes within each group. In the latter case genotypic variances for the PC (i.e., the respective eigenvalues) were compared by the homogeneity of variance test (Snedecor, 1964).

An ANOVA test was applied to compare the mean values for each variable in the NP and PRP groups in order to verify the principal component analysis.

\section{RESULTS}

No significant difference was found between $\mathrm{NP}_{1}$ and $\mathrm{NP}_{2}$ for any variable, indicating that there were no significant differences between years which influenced the expression of the traits. It was therefore possible to pool both subgroups in the NP sample.

No significant differences were detected by ANOVA between NP plants and PRP plants for PB, PM, PA and FC (Table II).

The first two PC (PC1 and PC2) accounted for a high proportion of the total variability (92\%) in NP plants (Table III). The subsequent PC had a small contribution to the whole and will not, therefore, be considered further. Figure 1A displays the NP plants following multivariate analysis on the basis of these two first PC.

Results corresponding to the PRP plants are shown in Table IV. The respective eigenvectors and eigenvalues were the same as those of the NP plants. PC1 and PC2 values for PRP plants are plotted in Figure 1B. In this case, associations of individuals were similar to those in NP plants.

No modification was observed when PC values were calculated for the total data (Table V). A similar arrangement of plants was again obtained (Figure 2). Additionally, it was not possible to observe any separation of the individuals according to their origin (i.e., regenerated plants vs. non-regenerated plants).

The first two eigenvalues of the PC by genotype are presented in Table VI. No significant difference among groups was detected by the homogeneity of variance test.

Table I - Genotypes of Lycopersicon investigated.

\begin{tabular}{|ll|}
\hline Species & Genotype \\
\hline Lycopersicon esculentum & cv. Nor (E1) \\
& cv. Platense Italiano (E2) \\
& cv. Caimanta (E3) \\
L. esculentum var. cerasiforme & LA 1385(C1) \\
& LA 1673(C2) \\
& Z 1994(C3) \\
L. pimpinellifolium & LA 722(Pi1) \\
L. peruvianum & Z1995(Pi2) \\
L. hirsutum & LA 2151(Pe1) \\
\end{tabular}

\section{DISCUSSION}

No modification was observed for the mean values and the variances of any trait in the progeny of the regenerated plants in respect to the non-regenerated plants. This fact was demonstrated by the ANOVA as well as by the multivariate analysis. However, the latter method would have additional advantages, since it would permit the in-

Table II - Mean values \pm standard deviation of the morphometric traits in the non-regenerated plants (NP) and in the progeny of the regenerated plants (PRP) by genotype of different Lycopersicon species.

\begin{tabular}{|c|c|c|c|c|c|}
\hline \multicolumn{2}{|c|}{ Genotype } & \multirow{2}{*}{$\frac{\mathrm{PB}}{3.23 \pm 0.23}$} & \multirow{2}{*}{$\frac{P M}{2.73 \pm 0.27}$} & \multirow{2}{*}{$\begin{array}{c}\mathrm{PA} \\
2.25 \pm 0.30\end{array}$} & \multirow{2}{*}{$\frac{\mathrm{FC}}{5.67 \pm 1.86}$} \\
\hline $\mathrm{El}$ & $\mathrm{NP}$ & & & & \\
\hline & PRP & $3.05 \pm 0.21$ & $2.55 \pm 0.21$ & $2.20 \pm 0.10$ & $4.50 \pm 2.12$ \\
\hline \multirow[t]{2}{*}{$\mathrm{E} 2$} & $\mathrm{NP}$ & $2.92 \pm 0.49$ & $2.69 \pm 0.29$ & $2.12 \pm 0.22$ & $5.15 \pm 1.07$ \\
\hline & PRP & $2.98 \pm 0.39$ & $2.70 \pm 0.61$ & $2.05 \pm 0.59$ & $6.50 \pm 1.29$ \\
\hline \multirow[t]{2}{*}{ E3 } & $\mathrm{NP}$ & $3.12 \pm 0.42$ & $2.78 \pm 0.35$ & $2.25 \pm 0.27$ & $4.33 \pm 0.52$ \\
\hline & PRP & $2.80 \pm 0.07$ & $2.24 \pm 0.13$ & $2.02 \pm 0.13$ & $3.60 \pm 0.55$ \\
\hline \multicolumn{2}{|c|}{ F-value } & $0.63^{\text {n.s. }}$ & $0.46^{\text {n.s. }}$ & $0.12^{\text {n.s. }}$ & $0.11^{\text {n.s. }}$ \\
\hline \multirow[t]{2}{*}{$\mathrm{Cl}$} & $\mathrm{NP}$ & $2.70 \pm 0.34$ & $2.37 \pm 0.30$ & $1.98 \pm 0.30$ & $10.00 \pm 2.53$ \\
\hline & PRP & $2.55 \pm 0.35$ & $2.18 \pm 0.27$ & $1.80 \pm 0.29$ & $10.12 \pm 2.85$ \\
\hline \multirow[t]{2}{*}{$\mathrm{C} 2$} & $\mathrm{NP}$ & $3.05 \pm 0.56$ & $2.50 \pm 0.44$ & $2.02 \pm 0.36$ & $8.33 \pm 1.75$ \\
\hline & PRP & $2.57 \pm 0.27$ & $2.02 \pm 0.30$ & $1.80 \pm 0.29$ & $7.38 \pm 1.12$ \\
\hline \multirow[t]{2}{*}{ C3 } & $\mathrm{NP}$ & $2.91 \pm 0.58$ & $2.23 \pm 0.59$ & $2.07 \pm 0.59$ & $7.57 \pm 2.07$ \\
\hline & PRP & $2.36 \pm 0.40$ & $1.98 \pm 0.29$ & $1.68 \pm 0.49$ & $5.80 \pm 0.45$ \\
\hline \multicolumn{2}{|c|}{ F-value } & $0.10^{\text {n.s. }}$ & $0.37^{\text {n.s. }}$ & $0.25^{\text {n.s. }}$ & $0.58^{\text {n.s. }}$ \\
\hline \multirow[t]{2}{*}{ Pi1 } & $\mathrm{NP}$ & $2.43 \pm 0.37$ & $1.69 \pm 0.25$ & $1.31 \pm 0.39$ & $8.57 \pm 1.51$ \\
\hline & PRP & $2.48 \pm 0.45$ & $1.95 \pm 0.24$ & $1.80 \pm 0.43$ & $7.75 \pm 0.96$ \\
\hline \multirow[t]{2}{*}{ Pi2 } & $\mathrm{NP}$ & $2.12 \pm 0.24$ & $1.72 \pm 0.21$ & $1.35 \pm 0.27$ & $13.50 \pm 2.42$ \\
\hline & PRP & $2.32 \pm 0.32$ & $1.81 \pm 0.27$ & $1.54 \pm 0.20$ & $13.20 \pm 2.35$ \\
\hline \multicolumn{2}{|c|}{ F-value } & $0.65^{\text {n.s. }}$ & $0.16^{\text {n.s. }}$ & $0.46^{\text {n.s. }}$ & $0.80^{\text {n.s. }}$ \\
\hline \multirow[t]{2}{*}{ Pe1 } & $\mathrm{NP}$ & $1.53 \pm 0.19$ & $1.06 \pm 0.34$ & $0.89 \pm 0.34$ & $9.11 \pm 2.42$ \\
\hline & PRP & $1.50 *$ & $0.50 *$ & $0.50 *$ & $7.00 *$ \\
\hline \multicolumn{2}{|c|}{ F-value } & $0.74^{\text {n.s. }}$ & $0.38^{\text {n.s. }}$ & $0.28^{\text {n.s. }}$ & $1.00^{\text {n.s. }}$ \\
\hline \multirow[t]{2}{*}{ H1 } & $\mathrm{NP}$ & $2.27 \pm 0.53$ & $1.64 \pm 0.30$ & $1.41 \pm 0.26$ & $13.57 \pm 2.23$ \\
\hline & PRP & $2.01 \pm 0.21$ & $1.56 \pm 0.23$ & $1.18 \pm 0.27$ & $13.89 \pm 1.76$ \\
\hline \multicolumn{2}{|c|}{ F-value } & $0.24^{\text {n.s. }}$ & $0.89^{\text {n.s. }}$ & $0.20^{\text {n.s. }}$ & $0.69^{\text {n.s. }}$ \\
\hline
\end{tabular}

List of genotypes by species: L. esculentum: E1: cv. Nor, E2: cv. Platense Italiano, E3: cv. Caimanta; L. esculentum var. cerasiforme: C1: LA 1385, C2: LA 1673, C3: Z 1994; L. pimpinellifolium: Pi1: LA 722, Pi2: Z 1995; L. peruvianum: Pe1: LA 2151; L. hirsutum: H1: LA 2128. PB: Stem perimeter at the base $(\mathrm{cm})$; PM: stem perimeter in the middle $(\mathrm{cm})$; PA: stem perimeter at the top $(\mathrm{cm})$; FC: mean number of flowers per cluster. *Data corresponding to only one plant. ${ }^{\text {n.s. }}$ Nonsignificant.

Table III - Principal components (PC), eigenvalues (E) and proportions of explained variances (EV) and accumulated variances (AV) for the nonregenerated plants (NP) of different Lycopersicon species.

\begin{tabular}{|lccrr|}
\hline & PC1 & PC2 & \multicolumn{1}{c|}{ PC3 } & \multicolumn{1}{c|}{ PC4 } \\
\hline PB & $0.53(0.91)$ & $0.25(0.21)$ & $-0.74(-0.33)$ & $-0.33(-0.11)$ \\
PM & $0.54(0.93)$ & $0.18(0.15)$ & $0.67(0.30)$ & $-0.48(-0.17)$ \\
PA & $0.55(0.94)$ & $0.13(0.15)$ & $0.09(0.04)$ & $0.81(0.28)$ \\
FC & $-0.35(-0.60)$ & $0.93(0.79)$ & $0.05(0.02)$ & $0.03(0.01)$ \\
E & 2.95 & 0.73 & 0.20 & 0.12 \\
EV & 0.74 & 0.18 & 0.05 & 0.03 \\
AV & 0.74 & 0.92 & 0.97 & 1.00 \\
\hline
\end{tabular}

Correlation coefficient between the PC and each variable in parentheses. For abbreviations see legend to Table II. 
A. Non-regenerated plants

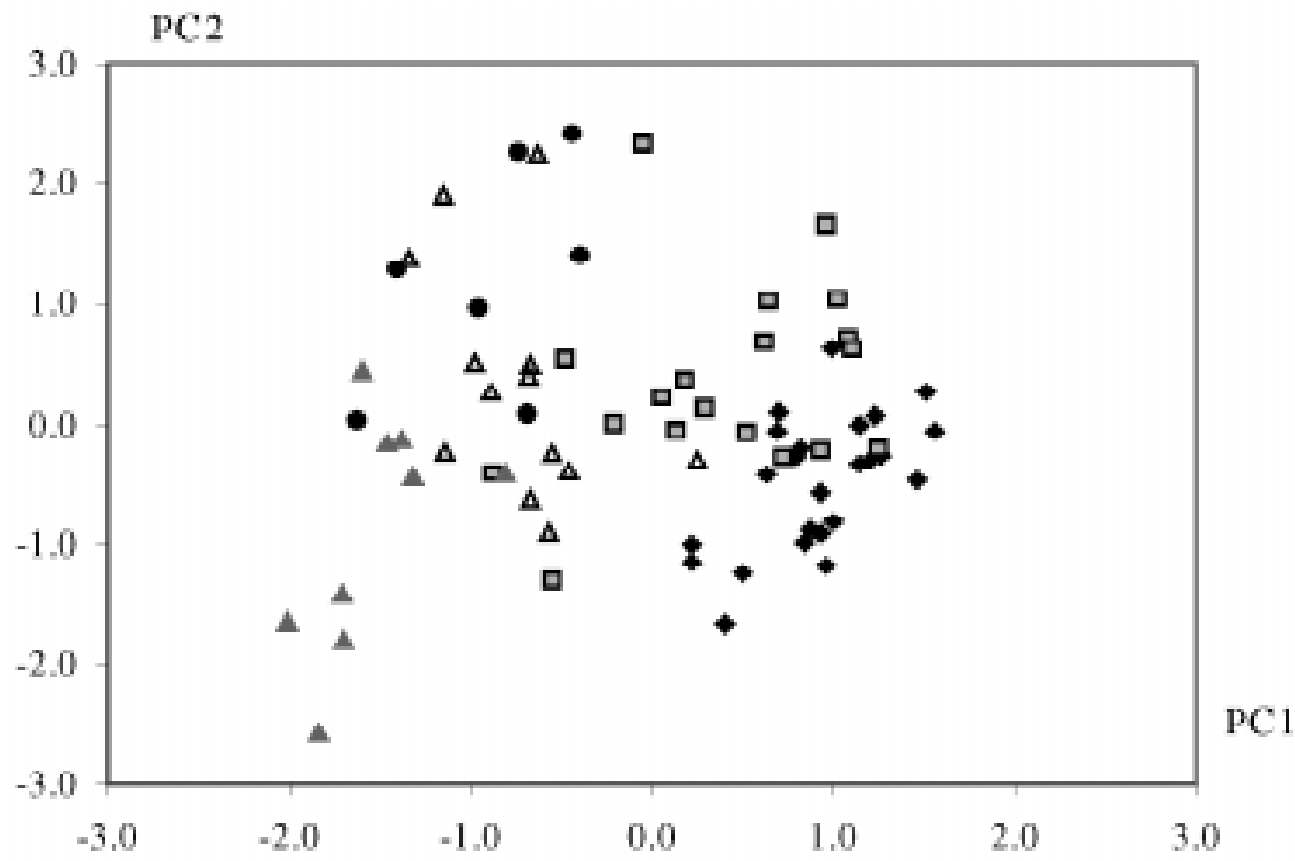

B. Progeny of the regenerated plants

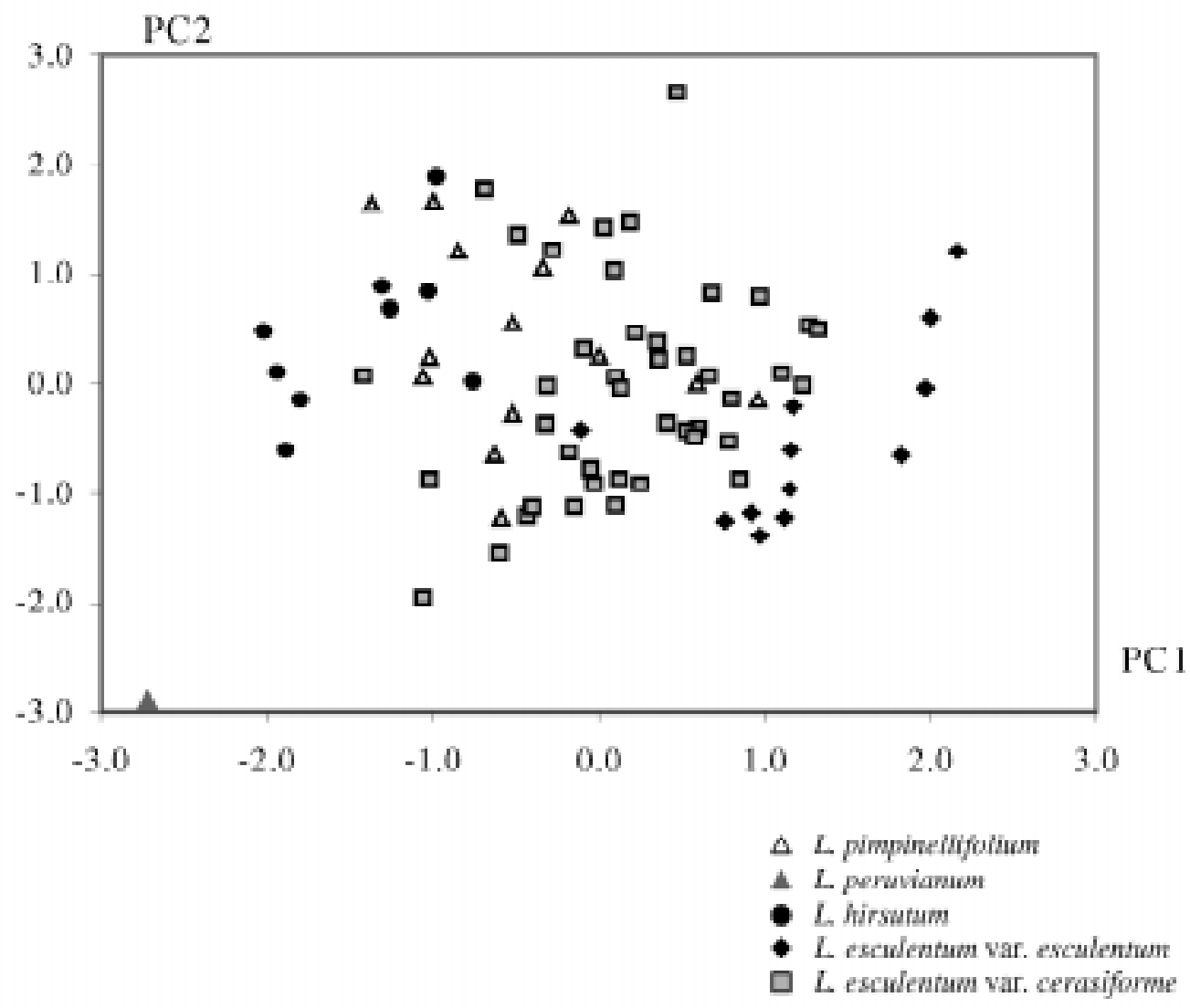

Figure 1 - Individual plants by species on the basis of principal component 1 (PC1) and principal component 2 (PC2). 
Table IV - Principal components (PC), eigenvalues (E) and proportions of explained variances (EV) and accumulated variances (AV) for the progeny of the regenerated plants (PRP) of different Lycopersicon species.

\begin{tabular}{|lcccr|}
\hline & PC1 & PC2 & PC3 & \multicolumn{1}{c|}{ PC4 } \\
\hline PB & $0.53(0.88)$ & $0.19(0.16)$ & $-0.71(-0.41)$ & $0.43(0.19)$ \\
PM & $0.54(0.90)$ & $0.12(0.10)$ & $0.70(0.40)$ & $0.45(0.20)$ \\
PA & $0.53(0.88)$ & $0.34(0.28)$ & $0.03(0.02)$ & $-0.77(-0.34)$ \\
FC & $-0.38(-0.63)$ & $0.91(0.76)$ & $0.04(0.02)$ & $0.14(0.06)$ \\
E & 2.78 & 0.70 & 0.33 & 0.19 \\
EV & 0.69 & 0.18 & 0.08 & 0.05 \\
AV & 0.69 & 0.87 & 0.95 & 1.00 \\
\hline
\end{tabular}

Correlation coefficient between the PC and each variable in parentheses. For abbreviations see legend to Table II.

Table V - Principal components (PC), eigenvalues (E) and proportions of explained variances (EV) and accumulated variances (AV) for all data (non-regenerated and progeny of regenerated plants) of different Lycopersicon species.

\begin{tabular}{|lcccr|}
\hline & PC1 & PC2 & PC3 & \multicolumn{1}{c|}{ PC4 } \\
\hline PB & $0.53(0.90)$ & $0.23(0.20)$ & $-0.72(-0.35)$ & $0.39(0.15)$ \\
PM & $0.54(0.92)$ & $0.15(0.13)$ & $0.69(0.34)$ & $0.45(0.17)$ \\
PA & $0.55(0.94)$ & $0.24(0.20)$ & $0.05(0.02)$ & $-0.80(-0.31)$ \\
FC & $-0.36(-0.61)$ & $0.93(0.79)$ & $0.05(0.02)$ & $0.04(0.02)$ \\
E & 2.89 & 0.72 & 0.24 & 0.15 \\
EV & 0.72 & 0.18 & 0.06 & 0.04 \\
AV & 0.72 & 0.90 & 0.96 & 1.00 \\
\hline
\end{tabular}

Correlation coefficient between the PC and each variable in parentheses. For abbreviations see legend to Table II. terpretation of the phenotypic structure (and any eventual changes) of the groups. In this case, PC1 may be considered as a general variability trait, since it represented about $74 \%$ of the total phenotypic variation observed in both groups and was highly correlated to all the variables. It allowed differentiation of the species according to the ratio vegetative development/reproductive development, and was positively associated with $\mathrm{PB}, \mathrm{PM}$ and PA, and negatively associated with FC. The species with high PB, PM and PA values and low FR values showed the greatest $P C 1$ values. For instance, L. esculentum and L. esculentum var. cerasiforme were both situated in the extreme right of the PC1 axis of both Figures 1 and 2. On the other hand, PC2 was narrowly associated to FC, which could be interpreted as a potential productivity factor. Even though PC2 explained a smaller percentage of the total variability $(18 \%)$, it permitted differentiation within the larger arrangements defined by PC1. Indeed, L. esculentum var. cerasiforme (which had a greater number of flowers per cluster) was situated above L. esculentum in both Figures 1 and 2. Also, L. pimpinellifolium and L. hirsutum were situated in the upper left quadrant of both Figures 1 and 2 while $L$. peruvianum was below them.

Multivariate analysis appeared to be an appropriate methodology for measuring the stability of metric traits after one regeneration cycle. Similar arrangement of NP plants and PRP plants based on the principal components was observed. These associations were preserved when analyzing all the data, suggesting that neither the means nor the variances of the regenerated plants were modified by effect of in vitro culture. It follows that both groups of plants

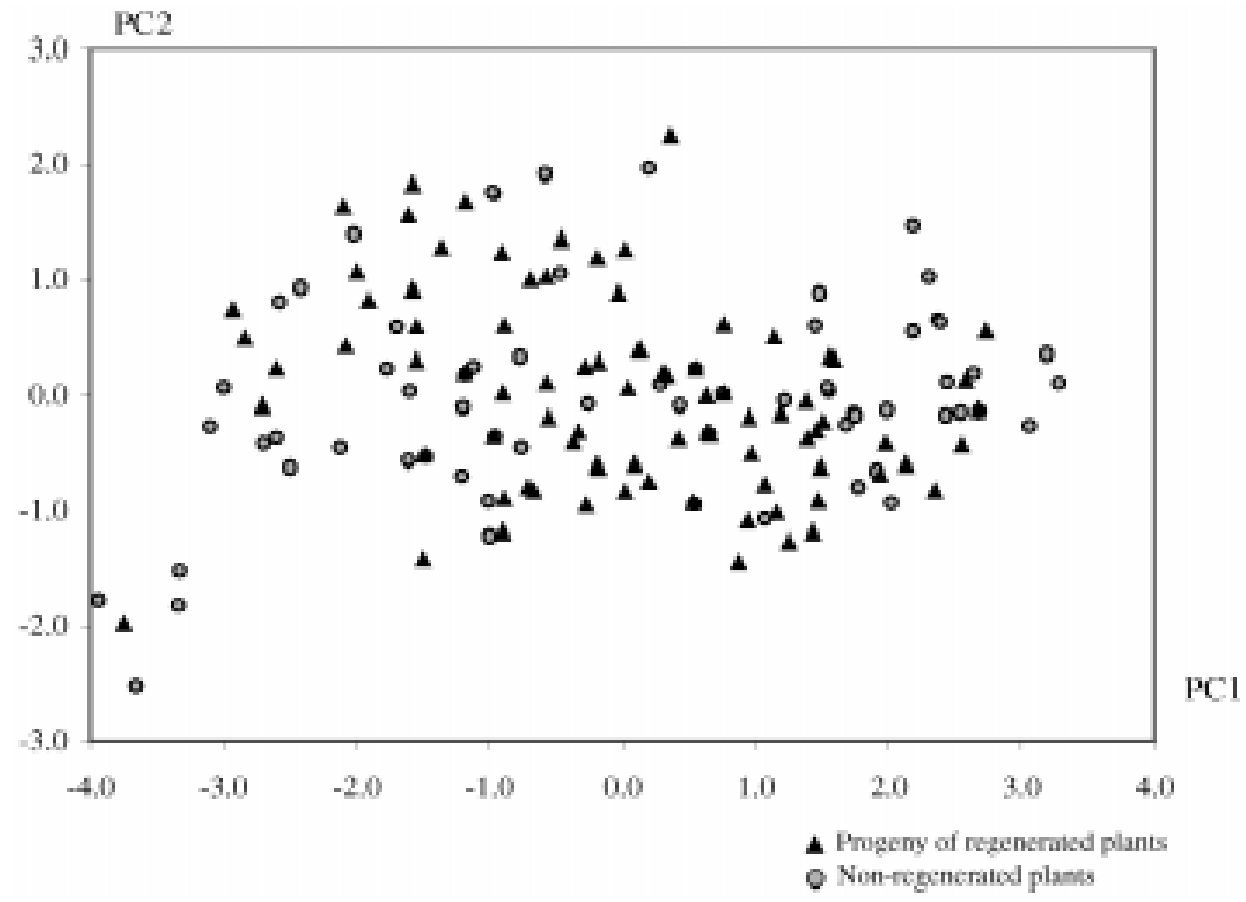

Figure 2 - Plot of the individuals on the basis of principal component 1 (PC1) and principal component 2 (PC2). 
Table VI - Eigenvalues $(\lambda)$ of principal component 1 and principal component 2 by genotype within group of different Lycopersicon species and F-values for the homogeneity of variance test.

\begin{tabular}{|lcccccc}
\hline \multirow{2}{*}{ Genotype } & \multicolumn{2}{c}{$\lambda_{1}$} & & \multicolumn{2}{c}{$\lambda_{2}$} \\
\cline { 2 - 3 } & NP & PRP & F-value & NP & PRP & F-value \\
\cline { 2 - 3 } & & & & & & \\
E1 & 1.91 & 2.47 & $1.29^{\text {n.s. }}$ & 1.26 & 0.59 & $2.14^{\text {n.s. }}$ \\
E2 & 1.91 & 2.26 & $1.18^{\text {n.s. }}$ & 1.24 & 1.71 & $1.38^{\text {n.s. }}$ \\
E3 & 2.55 & 2.00 & $1.28^{\text {n.s. }}$ & 0.94 & 1.05 & $1.12^{\text {n.s. }}$ \\
C1 & 2.26 & 2.17 & $1.04^{\text {n.s. }}$ & 1.32 & 0.93 & $1.42^{\text {n.s. }}$ \\
C2 & 2.40 & 2.11 & $1.14^{\text {n.s. }}$ & 1.10 & 0.96 & $1.15^{\text {n.s. }}$ \\
C3 & 2.66 & 2.91 & $1.09^{\text {n.s. }}$ & 1.00 & 0.74 & $1.35^{\text {n.s. }}$ \\
Pi1 & 2.04 & 2.77 & $1.36^{\text {n.s. }}$ & 1.12 & 0.86 & $1.30^{\text {n.s. }}$ \\
Pi2 & 1.90 & 1.52 & $1.25^{\text {n.s. }}$ & 1.72 & 1.31 & $1.31^{\text {n.s. }}$ \\
Pe1 & 3.31 & - & - & 0.54 & - & - \\
H1 & 3.15 & 2.53 & $1.25^{\text {n.s. }}$ & 0.79 & 0.94 & $1.19^{\text {n.s. }}$ \\
\hline
\end{tabular}

NP: Non-regenerated plants; PRP: progeny of the regenerated plants. For

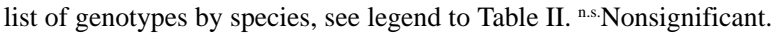

showed the same magnitude and source of variation in the phenotypic structure. According to De Klerk (1990), no variation would have been produced in the genetic systems influencing those traits.

\section{CONCLUSIONS}

No significant effect of in vitro culture on the morphometric traits was detected in Lycopersicon plants obtained from in vitro culture by principal component analysis.

Multivariate analysis is an appropriate methodology for the measurement of the stability of morphometric traits after one regeneration cycle.

\section{RESUMO}

Nesta experiência a estabilidade fenotípica dos caracteres métricos perímetro do culmo na base, no meio e no alto e número de flores por racemo foi medida mediante a prova de progênie com análise multivariada. Desta forma, uma nova metodologia para avaliação da estabilidade genética depois de um ciclo de regeneração in vitro foi proposta. Os componentes principais foram calculados para dois grupos de plantas de Lycopersicon spp.: o não regenerado e a progênie das plantas regeneradas. A ANOVA foi empregada como controle da análise de componentes principais. As diferenças entre grupos não foram estatisticamente significantes para nenhum caráter. Ambos os grupos apresentaram autovalores e autovetores similares. Os resultados obtidos indicaram que a estrutura fenotípica das plantas não foi modificada. Assim, nenhuma variação foi causada pela cultura in vitro. A análise multivariada mostrou ser uma metodologia apropriada para a medida da estabilidade dos caracteres métricos depois de um ciclo de regeneração.

\section{REFERENCES}

Chatfield, C. and Collins, A.J. (1986). Introduction to Multivariate Analysis. Chapman and Hall, London.

D'Amato, F. (1985). Cytogenetics of plant cells and tissue cultures and their regenerates. Plant Sci. 3: 73-112.

De Klerk, G.J. (1990). How to measure somaclonal variation. Acta Bot. Neerl. 39: 129-144.

Evans, D.A. and Sharp, W.R. (1983). Single gene mutation in tomato plants regenerated from tissue culture. Science 221: 949-951.

Gavazzi, G., Tonelli, C., Todesco, G., Arreghini, E., Raffaldi, F., Vecchio, F., Barbuzzi, G., Biasini, M.G. and Sala, F. (1987). Somaclonal variation versus chemically induced mutagenesis in tomato (Lycopersicon esculentum L.). Theor. Appl. Genet. 74: 733-738.

Lee, M. and Phillips, R. (1988). The chromosomal basis of somaclonal variation. Ann. Rev. Plant Physiol. 39: 413-437.

Pratta, G., Zorzoli, R. and Picardi, L.A. (1995). Adaptation of Lycopersicon plants from in vitro culture. Comun. Biol. 13: 448 (Abstract).

Pratta, G., Zorzoli, R. and Picardi, L.A. (1997). Intra- and interspecific variability of in vitro culture response in Lycopersicon (tomatoes). Braz. J. Genet. 20: 75-78.

Skirvin, R.M., Cheeters, K.D. and Norton, M. (1994). Sources and frequency of somaclonal variation. HortScience 29: 1232-1237.

Snedecor, G. (1964). Métodos Estadísticos. 5ta Edición. Companía Editorial, México D.F.

(Received January 20, 2000) 
